\section{VOTEPOW: A computer program for the measurement of voting power using roll call data}

\author{
HARVEY W. KUSHNER \\ Department of Politics, New York University \\ New York, New York 10003
}

and

\section{ARNOLD B. URKEN \\ Department of Humanities, Stevens Institu te of Technology Hoboken, New Jersey 07030}

VOTEPOW uses combinatiorial mathematics to generate three a posteriori measures for the power in voting bodies, based on a model created by Brams (1972) of New York University. Using roll-call data as input, the program produces a measure of individual voting power and two measures of conditional or relational voting power (Kushner \& Urken, 1973).

Output. The first piece of output generated by VOTEPOW is a listing of individual voting power ratings for all actors of a voting body. The individual voting power of an actor is defined as that probability that the preference of an actor, $i$, will agree with the majority outcome across a set of roll calls, i.e., P(i). For example, an actor who votes with the majority on nine out of nine roll calls would have an individual voting power of 1.00 , since the voter's chance agrees with the majority outcome on all roll calls.

The second measure [pairwise probabilistic power (PDIFF)] generated by VOTEPOW is a conditional or relational measure of voting power. This measure represents the influence of pairwise agreement or disagreement with other actors on an actor's chances of being on the winning side, i.e., voting with the majority. Thus, conditional probability gauges the extent to which the actors $i$ and $j$ sustain majority outcome, given that they agree $(\mathrm{AG})$ with each each other $\left[\mathrm{P}\left(\mathrm{i}, \mathrm{j} \mid \mathrm{AG}_{\mathrm{i}, \mathrm{j}}\right)\right]$; and conditional probabilities that, given that $i$ and $j$ disagree (DG) with each other. $i$ votes with the majority $\left[\mathrm{P}\left(\mathrm{i} \mid \mathrm{DG}_{\mathrm{i}, \mathrm{j}}\right)\right]$, or $\mathrm{j}$ votes with the majority $\left[\mathrm{P}\left(\mathrm{j} \mid \mathrm{DG}_{\mathrm{i}, \mathrm{j}}\right)\right]$. These conditional probabilities enable us to obtain a measure which represents the difference that agreement or disagreement makes on each actor's chances of being on the winning side. For example, for Actor i,

$$
\operatorname{PDIFF}_{i \mid j}=P\left(i, j \mid A G_{i, j}\right)-P\left(i \mid D G_{i, j}\right),
$$

and for Actor $\mathrm{j}$,

$$
\operatorname{PDIFF}_{j l i}=P\left(i, j \mid A G_{i, j}\right)-P\left(j \mid D G_{i, j}\right) \text {. }
$$

To illustrate the calculations involved, let us assume that
Actors $\mathrm{i}$ and $\mathrm{j}$ agree together on three votes and are sustained by the majority twice, and they disagree on two votes with each other being on the winning side once. Thus, for Actors i and j, the PDIFF values are:

$$
\begin{aligned}
& \operatorname{PDIFF}_{\mathrm{i} \mid \mathrm{j}}=(2 / 3-1 / 2)=.17 \\
& \operatorname{PDIFF}_{j \mid \mathrm{i}}=(2 / 3-1 / 2)=.17
\end{aligned}
$$

The last piece of output generated by VOTEPOW is E(PDIFF), a measure of the expected probabilistic difference that agreement of disagreement can make in relation to the relative frequencies with which two actors agree or disagree with the majority outcome over a set of roll calls. In order to account for this factor, the third measure incorporates unconditional probabilities of agreement and disagreement $\left[P\left(\mathrm{AG}_{\mathrm{i}, \mathrm{j}}\right)\right.$ and $\left.\mathrm{P}\left(\mathrm{DG}_{\mathrm{i}, \mathrm{j}}\right)\right]$ as weights in the PDIFF measure to give an expected value for PDIFF [E(PDIFF)]. For member i,

$$
\mathrm{E}(\mathrm{PDIFF})_{\mathrm{i} \mid \mathrm{j}}=\mathrm{P}\left(\mathrm{AG}_{\mathrm{i}, \mathrm{j}}\right) \mathrm{P}\left(\mathrm{i}, \mathrm{j} \mid \mathrm{AG}_{\mathrm{i}, \mathrm{j}}\right)-\mathrm{P}\left(\mathrm{DG}_{\mathrm{i}, \mathrm{j}}\right) \mathrm{P}\left(\mathrm{i} \mid \mathrm{DG}_{\mathrm{i}, \mathrm{j}}\right)
$$

and for member $\mathrm{j}$,

$$
\mathrm{E}(\mathrm{PDIFF})_{\mathrm{j} \mid \mathrm{i}}=\mathrm{P}\left(\mathrm{AG}_{\mathrm{i}, \mathrm{j}}\right) \mathrm{P}\left(\mathrm{i}, \mathrm{j} \mid A \mathrm{AG}_{\mathrm{i}, \mathrm{j}}\right)-\mathrm{P}\left(\mathrm{DG}_{\mathrm{i}, \mathrm{j}}\right) \mathrm{P}\left(\mathrm{j} \mid \mathrm{DG}_{\mathrm{i}, \mathrm{j}}\right) \text {. }
$$

To illustrate the calculations involved in obtaining E(PDIFF), let us assume that Actors $i$ and $j$ agree on three out of five roll calls (and are sustained by the majority twice), and they disagree on two out of five roll calls (with each actor being on the winning side once). The E(PDIFF) values are as follows: For Actor i,

$$
\mathrm{E}(\mathrm{PDIFF})_{\mathrm{i} \mid \mathrm{j}}=[(3 / 5(2 / 3)]-[(2 / 5)(1 / 2)]=.20
$$

and for Actor $j$,

$$
\mathrm{E}(\mathrm{PDIFF})_{\mathrm{j} \mid \mathrm{i}}=[(3 / 5)(2 / 3)]-[(2 / 5)(1 / 2)]=.20 .
$$

The PDIFF and E(PDIFF) measures can be used to define power relationships between actors which are not intuitively obvious (Kushner \& Urken, 1973). It may eventually be possible to reconstruct coalition-formation processes by using PDIFF and E(PDIFF) measures. This type of exercise may lead to some interesting conclusions about the actual coalition-formation process vis-a-vis the theoretical influence relationships analyzed in voting bodies (Brams, 1972).

Computer and Language. VOTEPOW is written in basic FORTRAN IV for an IBM System/360 computer. The running time depends on the size of the voting body and the number of roll calls analyzed.

Input.' In addition to providing roll call data, the user must supply (1) the size of the voting body and the number of majority outcomes; (2) the boundaries of the 
number of actors (M) and majority outcomes $(\mathrm{N})$; (3) the manner in which boundaries $\mathrm{M}$ and $\mathrm{N}$ are to be read in on data cards; and (4) the different voting options.

Availability. VOTEPOW program deck can be obtained free of charge from New York University, Academic Computer Center, 725 Commerce Building, Washington Square, New York, New York 10003. All questions concerning the interpretations of VOTEPOW can be addressed to the authors of this report.

\section{REFERENCES}

Brams, S. J. Reconstructing coalition-formation processes and influence structures from roll-call votes. N ew $Y$ ork University, 1972.

Kushner, H. W., \& Urken, A. B. Measuring power in voting bodies. Public Choice, 1973, 15, 77-85.

\section{PARSUPPORT: A computer program for measuring the support of a party member for his party}

HARVEY W. KUSHNER

Department of Politics, New York University New York, New York 10003

PARSUPPORT uses combinatorial mathematics to generate an a posteriori probabilistic measure of party support by an individual in a voting body. Roll call data is used as input to ascertain the support score percentage (SSP) of a party member for his party. The party position is defined to be that position which a majority of party members support.

PARSUPPORT will generate a listing of SSPs for all party members. The SSP of a party member, $i$, is defined as the probability that Member $i$ votes in agreement with the majority of his party across a set of roll calls. But the set comprises only roll calls of which a distinct party preference is determinable. That is, tied outcomes are discounted.

The SSP can be used to ascertain the probability of a party member's support of party voting in respect to ideologically defined issues (De Maio \& Kushner, 1972). In addition to denoting the probability of a party member's agreement with the party position, it is also possible to use the measure to denote the difference between subgroups within the party, e.g., southern Democrat. By dividing the party into subgroups, it becomes possible to ascertain the SSP of a party member in respect to the subgroup as well as the whole party. The researcher is left free to develop different sets of subgroups which can lead to some interesting findings. Among the most interesting findings would be those that are not intuitively obvious (De Maio \& Kushner, 1973).

Computer and Language. PARSUPPORT is written in basic FORTRAN IV for an IBM System/360 computer. The size of the data matrix determines the running time. In addition to providing roll call data, the user must (1) adjust the DIMENSION statement if the matrix is larger than $100 \times 600$, i.e., 100 party members and 600 roll calls; (2) set the boundaries on the number of party members and roll calls; and (3) set the different voting options.

Availability. A copy of a PARSUPPORT program can be obtained free of charge by writing the New York University Academic Computer Center, 725 Commerce Building, Washington Square, New York, New York 10003. All questions concerning the interpretations of PARSUPPORT can be addressed to the author of this report.

\section{REFERENCES}

De Maio, G., \& Kushner, H. W. Can a voter employ an ideological differential in selecting congressional representation. New York University, 1972.

De Maio, G., \& Kushner, H, W. Marginal-switch districts and ideological voting. New York University, 1973. 